\title{
The Acquisition of Spanish Perfective Aspect: a study on children's production and comprehension*
}

\author{
Miren Hodgson \\ University of Massachusetts, Amherst \\ mhodgson@spanport.umass.edu \\ mhodgson@berkshire.rr.com
}

\begin{abstract}
This paper presents the acquisition of Spanish perfective aspect in production and comprehension. It argues that, although young children use perfective aspect to talk about completed events, young children have difficulty in assessing perfective meaning from perfective morphology. This paper proposes that in the process of acquiring aspectual meaning, children use local strategies to decode aspectual meaning from form: when analyzing a completed situation, young children depend on certain learnability factors to correctly assess the entailment of completion of the perfective, namely, their ability to determine if the object of the event measures out the event as a whole or not, and their ability to read the agent's intentions. When those factors are removed from the situation, young children had difficulty determining the entailment of completion of perfective aspect. This study also suggests that the manner in which aspectual information is conveyed in a language, may play a role on the readiness of the acquisition of the semantic morphology of the language (e.g., verb+object vs. verb+affixes). The results of this study indicate that successful performance on the semantics of Spanish perfective aspect develops around the age of 5-6.
\end{abstract}

\section{$1 \quad$ Introduction}

Aspect expresses the internal compositional meaning of a sentence. According to the literature, aspectual meaning is conveyed by two independent components, lexical aspect, which is determined by the lexical properties of the whole verb phrase, and grammatical aspect, which is determined by the verbal system of the language, which includes tense and aspect morphology ${ }^{1}$.

Lexical aspect refers to the inherent semantic properties displayed by the verb and its arguments in a sentence. These properties are defined as contrasting sets, telic/atelic, stative/ dynamic, and instantaneous/durative. Vendler's $(1957)^{2}$ verb classification distinguishes verbs

* I thank Tom Roeper, Barbara Pearson, and the members from the UMASS Acquisition Group for their insightful comments and discussion of the research presented here. I am very grateful to Josep Manonelles, and Manuel Roncal Lozano, the directors of the schools that allowed me to carry on this study, and for their continued support on the research of language acquisition. I am especially thankful to the children and adults that may this research possible, the children from Estudio Primario Al'zina in Barcelona, and the children from Obra Diocesana Santo Domingo de Silos in Zaragoza. I also want to thank the audience at the Workshop on the Acquisition of Aspect at Zentrum für Allgemeine Sprachwissenschaft (ZAS), Berlin, where this research was presented.

1 The terms lexical and grammatical aspect have been identified in the literature as inner and outer aspect, Verkuyl (1987); situation time and point of view, Smith (1991/1997); and, (a)telicity and (un)boundedness, Depraetere (1995)respectively.

2 Vendler's classification of events was inspired by the old Aristotelian tripartition of situational types. 
according to their lexical inherent properties: States (e.g., love, think), Activities (e.g., run, play), Accomplishments (e.g., eat, write), Achievements (e.g., win, climb). The lexical property that concerns us in this study is the property of telicity ${ }^{3}$. A predicate is telic when the event that it denotes reaches its point of culmination, in other words, when it entails the completion of an event as in build the house, play basketball for an hour, write a letter. The entailment of completion obtained in a telic predicate is determined by the theme argument of the verb, which must be realized as a direct object of quantized reference and therefore, must appear in a transitive verb frame. A predicate is atelic when the event that it denotes does not reach its point of culmination, instead, it denotes an arbitrary ending as in, build houses, play basketball, write letters. Notice that these predicates although in a transitive verb frame, do not entail the completion of the event, this is due to the direct object's non-quantized reference. Grammatical aspect refers to aspectual distinctions of the language, which specify the boundaries of an event. Grammatical aspect is usually marked by auxiliaries, and by the inflectional or derivational morphology of the language. For example, in English, a perfective reading is obtained by the use of the morpheme -ed as in he played basketball. A progressive imperfective reading is obtained by using the auxiliary be and -ing as in he is playing basketball. While the perfective focuses on the initial and final boundary of the event, the progressive imperfective, on the other hand, focuses on an ongoing action without indicating the initial or final boundary of the event. The aspectual meaning of a sentence is, therefore, construed on the interaction of the two types of aspect, lexical and grammatical. However, analysis on the interaction of the two components indicates that imperfective grammatical aspect overrides lexical aspect, a phenomenon known as the imperfective paradox, Dowty (1979). For example, the use of imperfective aspect in either telic or atelic verb phrase entails an event in progress (e.g., John was building the house; John was playing basketball). By contrast, the use of perfective aspect in a telic verb phrase entails the completion of the event (e.g., John built the house), whereas in an atelic predicate, entails an arbitrary end, i.e., an event that has terminated (e.g, John played basketball).

The interaction of grammatical aspect and lexical aspect has been the center of much interest in the field of language acquisition-both, first and second language acquisition-because it stands at the interface between the lexicon and the grammar. Therefore, it provides researchers with information in the manner which semantic meaning assists on the acquisition of grammatical categories. The ability to distinguish between the aspectual classes, and to talk about time is of vital importance. Research on the acquisition of aspect has shown that children begin producing aspectual morphology as early as 2;6 years of age, and that they restrict grammatical aspect according to lexical aspect. In other words, young children use imperfective morphology with atelic verbs, and perfective morphology with telic verbs. Thus, young learners of English, for example, produce forms like playing and running (atelic + imperfective), and, made and broke (telic + perfective) in their early sentences, and not played and ran, or making and breaking. The distribution of grammatical aspect according to lexical aspect has been reported in several languages, among them, French, Bronckart and Sinclair (1973); Italian, Antinucci and Miller (1976); English, Bloom, Lifter and Hafitz (1980); Portuguese, DeLemos (1981); Japanese, Rispoli (1981); Hebrew, Berman (1983); Polish, Weist et al (1984); Turkish, Aksu-Koc (1988); Mandarin, Li (1990); German, Behrens (1993).

Although studies have shown that children's production of aspectual morphology is acquired at an early age, children's comprehension of aspect, on the other hand, has presented contradictory results as to the age of acquisition of aspectual semantic morphology. Studies in Polish, Weist et al (1984/1991), and in Russian, Stoll (1998), Vinnitskaya and Wexler (2001),

The term 'telic' used to describe a property of telicity, was first introduced by Garey (1957), and it is derived from the Ancient Greek télos which means end. 
young subjects performed well. Yet, studies in English, Wagner (1997/2002), and in Dutch, van Hout (1998/ in press), young children had difficulties in assessing meaning from form. It appears then, that perfective morphology is acquired at an early age, and in some languages like Polish and Russian, the comprehension of perfective aspectual semantics reflects the production. However in other languages like English and Dutch it does not, that is, he comprehension of aspectual meaning appears to develop at a later age than aspectual morphology.

This article discusses children's acquiring ability of Spanish perfective aspect in production as well as in comprehension. The research questions leading this study are, if children's aspectual semantics of the Perfective develops at a later age than aspectual morphology, what linguistic and cognitive principles are involved to cause the apparent mismatch between comprehension and production? What do children know about Spanish Perfective aspect of telic verbs? What do children need to know to correctly assess Spanish Perfective meaning from form? And finally, is the acquisition of semantic morphology in one language easier to acquire than in another language because its morphology is more readily attainable? And if that is the case, what language particular morphological elements are involved that foster the acquisition of aspectual semantics? According to the findings of this study, I will argue that, although young children are able to produce perfective morphology to describe telic predicates, they lack the semantic knowledge necessary to decode the meaning from the form. Young children rely on strategies such as checking if the direct object totally meted out the event, and reading the agent's intentions. These strategies play a role on the discovery of Spanish semantic meaning.

Section 2 presents how perfective aspect is marked in Spanish. Section 3 describes the experiment and presents the results from the production and comprehension studies on Spanish perfective aspect. Section 4 discusses the results and proposes learnability issues that resulted from the experiment.

\section{Background on Spanish Perfective Grammatical Aspect}

Grammatical aspect is a concept that expresses the temporal contour of a situation. Perfective grammatical aspect focuses on the initial and final boundaries of an event, and as such, it describes an event as a single whole. Spanish grammatical aspect is expressed through tense. The notions of tense and aspect become at times confused by the fact that many languages have the verb forms include specification of both aspect and tense, Spanish is one of such language. While grammatical aspect expresses the boundaries of a situation, tense informs the receiver of the time line on which a situation occurred, both aspect and tense are fused in the same morpheme and configure the verb-inflectional system of the language. For example, in the sentence Ana construyó un robot 'Ana built a robot', the morpheme -ó carries within, the temporal line, which is this case is past time, and the aspectual temporal contour -initial and final, indicating that the robot building event was completed. The perfective tenses most commonly used are Pretérito Indefinido, simple past, and, Pretérito Perfecto, present perfect ${ }^{4}$.

Following Vendler's (1957) verb classification, the interaction of Spanish perfective grammatical aspect in the preterite with lexical aspect is as follows:

(1) a. Don Gustavo pensó en ella.

(State)

'Don Gustavo thought of her.'

Other tenses in the perfective are the perfects. Past: pretérito anterior, pretérito pluscuamperfecto. Futures: futuro, and futuro perfecto. Conditional: Potencial. 
b. Liam caminó por el parque.

'Liam walked in the park.'

c. Liam tropezó con una piedra.

'Liam stumbled on a rock'

d. Don Gustavo le escribió una carta.

'Don Gustavo wrote her a letter.'
(Activity)

(Achievement)

(Accomplishment)

The use of the perfective in a sentence that denotes a state as in (1a), expresses that the event came to an end, i.e., the Spanish perfective expresses the endpoint of a stative sentence. The property of the perfective containing the endpoint of a sentence that expresses a state, departs from the norm in Universal Grammar. Prototypically, perfective aspect does not include the endpoint of a stative situation, i.e., in most languages, the use of perfective aspect in states does not indicate that the event reached an end, in that sense, the Spanish perfective departs from the norm and it becomes available in stative situations ${ }^{5}$. In (1b), the combination of perfective aspect with an activity verb phrase, yields an atelic predicate and therefore, a terminated event, i.e., an incomplete event. In (1c), the use of the perfective in an achievement verb phrase focuses on the endpoint of the situation, yielding a telic predicate. Sentence (1d) also describes a telic predicate because it denotes the entailment of completion: when the letter is written, the event is completed. When a perfective tense such as the preterite is used in such predicates, the perfective emphasizes the entailment of completion by presenting the situation as a single whole. This is due to the perfective's ability to mark the initial and final endpoint of a situation that contains a direct object of incremental theme such is "write a letter.'

\section{The Acquisition of Spanish Perfective Aspect}

In a study of grammatical aspect, I have tested the production and comprehension of perfective aspect in accomplishment situations of 77 native Spanish children and 15 adults. The production task was based on Bronckart and Sinclair's (1973) experiment and investigates children's distribution of grammatical aspect morphology. This experiment was presented in digital video format in the computer's CD-ROM. Children were presented with a short movie, which they had to describe when the movie was over. Therefore, the selection of grammatical aspect (e.g., perfective or imperfective) was the subject's choice. The goal of the comprehension tasks was to investigate if the presence or absence of the agent and theme (object) plays a role on children's acquisition of semantic meaning. In both comprehension tasks, the subjects were presented with a context, a story that described the context, and a question stated in the perfective relevant to only one of the outcomes of the context. The first comprehension task was also a digital video presentation and it consisted of two events, in which the agents of each event are seen involved in the action of the event. In one of the events, the outcome of the event is completely shown, i.e., the change of the state of the object is shown, in the other event, it is partially shown. The second comprehension task was not presented in digital video format, instead, it consisted of toys and pictures. In this task, the agents were never seen involved in the action of the event, neither were they present in the outcome of the event. The change of state of the object was completely shown to the participants.

Other Romance language in which the perfective is also available for states is French, Smith (1997). 


\subsection{Experimental Design of the Production Task}

\section{Subjects}

Fifteen native adult speakers and thirty-three children participated in the study: eleven 3-4 year-olds; eleven 5-6 year-olds; eleven 7-8 year-olds. The adults were tested at their homes, and the children were tested at school and at home in Barcelona, Spain.

\section{Materials}

The materials consisted of silent digital video actions presented to the subject in a computer screen that described three telic verbs alternated with three atelic verbs. The three actions that represented telic verbs were: a cow crosses a river, a horse jumps an obstacle bar, and a girl stacks two blocks. The actions that represented the atelic verbs were: a girl rides a scooter, a dog plays with a ball, and a boat sails in the river. The HORSE JUMPS AN OBSTACLE BAR event, for example, described a telic verb phrase and consisted of a hand-guided horse toy that runs towards two obstacles, jumps each one at a time, turns around, and jumps another obstacle. The GIRL RIDES A SCOOTER event described an atelic predicate and consisted of a hand-guided toy that rides a scooter on the background of a park. All the other events were acted out in a similar way on a table that had a background of a park and a small river. Within each event, the actions were repeated, for example, in the jumping event, the horse jumps over three obstacles; in the riding event, the girl rides around making several turns. The objective of having the toys repeat the same action more than once, was to help the children remember the action so they could describe the event more vividly. Each event was filmed individually with a digital camera, imported to a computer where it was copied onto a CD-ROM.

\section{Procedure}

Before the experiment was carried out, the subjects were presented with a trial test. The objective of this test was to see if the child was ready for the task, and to help the child to be familiar to what he was going to watch. The child's task, for both the trial test and the actual experiment, was to describe the situation when it was over. In describing the situation, the participant would have to select how he wants to convey the information. The subject has two choices, he can express himself by using perfective morphology or by using imperfective morphology. The children were presented with the actual toys acting out an event, for example a horse playing with a toy, a dog crossing the river, etc., and were asked to describe the event. Once the child was familiar with the procedure, the subject was told the following: we are going to watch a short movie on the computer screen about these toys. I need you to pay a lot of attention, because when the movie is over, you are going to tell me what you saw. Each individual participant was then presented with the movie. At the end of the movie, he or she was told 'tell me'. At that point, the subject described the event. Each participant was tested individually in a quiet place in all six events. The adult participants were presented with the same procedure except for the trial test. The children that did not perform well on the trial test did not take part in the experiment. These were, either children that couldn't communicate very much because of their age (some $2-2 ; 5 \mathrm{yr}$-olds), or children that were too timid to express themselves.

\section{Results}

Tables 1 and 2 represent the percentages of tenses used to describe telic aspectual type situations and atelic aspectual type situations for each age group of children and for adults 6 .

6 As a clarification of some of the abbreviations used on the tables, in Spanish, the imperfect progressive is formed by the auxiliary estar in the imperfect form, and a present participle, just like the English be + ing (e.g., estaba saltando, 'was jumping'). The imperfect is the simple past but in the imperfective, English does not have this tense (e.g., saltaba, 'was jumping'). The term Progressive refers to the present participle, 
Table 1. Telic Aspectual Type in \%

\begin{tabular}{|c|c|c|c|c|c|c|c|c|}
\hline Age & Preterite & Perfect & Present & Imp. Prog. & Imperfect & t Progres. & Pres. Prog & RIs \\
\hline Adults & 62 & 20 & 11 & 0 & 4 & 0 & 2 & 0 \\
\hline $3-4$ & 42 & 24 & 0 & 15 & 6 & 3 & 0 & 6 \\
\hline $5-6$ & 27 & 21 & 0 & 9 & 18 & 0 & 9 & 15 \\
\hline $7-8$ & 36 & 48 & 6 & 0 & 6 & 3 & 0 & 0 \\
\hline
\end{tabular}

Table 2. Atelic Aspectual Type in \%

\begin{tabular}{lccccccccc} 
Age & Present & $\begin{array}{c}\text { Imp. } \\
\text { Prog. }\end{array}$ & \multicolumn{1}{l}{ Imperfect Progres. Pres. Prog Preterite } & Perfect Pre.Pf.Pro & RIs \\
\hline \hline Adults & $\mathbf{1 8}$ & $\mathbf{9}$ & $\mathbf{2 4}$ & $\mathbf{1 8}$ & $\mathbf{1 8}$ & 6 & 2 & 4 & 0 \\
$3-4$ & $\mathbf{6}$ & $\mathbf{3 3}$ & $\mathbf{2 1}$ & $\mathbf{3}$ & $\mathbf{1 2}$ & 6 & 0 & 0 & 15 \\
$5-6$ & $\mathbf{3}$ & $\mathbf{3 6}$ & $\mathbf{3 6}$ & $\mathbf{9}$ & $\mathbf{3}$ & 3 & 0 & 0 & 12 \\
$7-8$ & $\mathbf{0}$ & $\mathbf{4 5}$ & $\mathbf{1 5}$ & $\mathbf{1 5}$ & $\mathbf{0}$ & 0 & 12 & 0 & 6 \\
\hline \hline
\end{tabular}

Adults used perfective tenses, namely, the preterite and the present perfect $82 \%$ of the time to describe completed situations, and use imperfective tenses to express incomplete situations $87 \%$, which accounts for the following tenses: the present, the imperfect progressive, the imperfect, the progressive, and the present progressive. The youngest group, the 3-4 yr-olds used perfective tenses $66 \%$, which is above average, but non-target like performance in describing completed situations, however, they performed at the $75 \%$ rate in expressing incomplete situations with imperfective tenses, which is considered within target like behavior. The 5-6 yr-olds used the imperfect tense and the imperfect progressive tense 36\%, used root infinitives $15 \%$, and only produced perfective tenses $48 \%$ when talking about completed situations. These children performed below chance. However, they performed at the $87 \%$ ratio when relating incomplete events, which is well within target. The 7-8 year-olds' performance followed the adult's performance, they produced $84 \%$ perfective tenses in their description of completed situations, while they used imperfective tenses in incompleted events $75 \%$ of the time.

\section{Interpretation of the results of the production task}

Adult's results indicate that adults distributed grammatical morphology according to lexical type. Young children followed similar pattern, however, their performance was just below target in the use of perfective tenses in situations that described telic predicates. Children 5-6 overused imperfectives in completed situations. The question arises as to why the 5-6 yearolds overextended the imperfective to express telic situations? A possible explanation is that since the Spanish imperfect tense and the imperfect progressive tenses are used as narratives to describe the past, children at the age of 5-6 are using the tenses as narratives and they don't quite know the entailment of non-completion that the tenses carry. Given the context of the experiment setting, these children decided to tell us a story instead of expressing themselves in a factual mode. Also notice that these children used more root infinitives than the other two groups of children $15 \%$ (compare with $6 \%$ of the 3-4 yr-olds), which indicates that some of these children did not know what tense to use to describe a completed situation. The oldest

like the English -ing form (e.g., saltando, 'jumping'). Present Progressive is the combination of the auxiliary estar in the present form, and the present participle, like in English be + ing (e.g., está saltando 'is jumping'). RIs refer to root infinitivals. In table 2, the term present perfect progressive represents the auxiliary haber, the past participle estar, and a present participle; in English have + be and -ing (e.g., ha estado saltando, 'has been jumping'). 
group 7-8 year-olds performed like the adults in their use of perfective tenses in completed events.

Concerning the use of imperfective tenses to describe non-completed events, overall, children performed better than in using perfectives to describe completed situations. This may suggest that when talking about completed events, children have to be aware of the syntactic and semantic realizations of the sentence arguments as for example how the direct object relates to the rest of the sentence and how it measures out the event. In describing incomplete events, children have one less variable to factor out in their semantic calculation, namely, the direct object. A language like Spanish, in which the use of imperfective tenses is not based on pragmatic considerations like in Russian or Polish, children may have an easier time acquiring the semantics of imperfect aspect due to the less number of restrictions upon the use of imperfectives when expressing incomplete events.

\subsection{Experimental Design of Comprehension Task I}

\section{Subjects}

Fifteen adults and forty-four children native speakers of Spanish participated in the study. The 3-4 year-old group consisted of 14 subjects, the 5-6 year-old consited of 17 subjects, and the 7-8 year-old was made of 13 subjects. The adults were tested at their homes, and the children were tested at school at two locations, Barcelona and Zaragoza, Spain.

\section{Procedure and Materials}

The participant child was first tested in a trial test. The objective of the trial test is to help the child become familiar with the experimental procedure to assure his cooperation in the real test. Both, the trial test and the actual experiment, consisted of a story that describes a situation and a question in the perfective presented at the end of the story. The child's task, for both trial and experiment, is to match the question with the completed event. The trial test introduces the participant to characters involved in actions that described telic predicates plus an adjective that emphasizes the entailment of completion, e.g., fill an entire bucket, write a whole letter. The trial test was presented to the subject in picture format instead of digital video. For example, the subject is told that we are going to play a guessing game, and at the end of the game, he is going to answer a question. The subject is then introduced to two characters, one of them is filling a bucket with water. In the next picture set, the participant is presented with a picture of two buckets, one completely full and the other half full. Then the other character says, 'Billy said that he filled the entire bucket of water', the participant is then asked, can you tell me which bucket Billy filled? The subjects that did not pass the trial tests, or had difficulties understanding the procedure did not take part in the experiment, most of these children belonged to the youngest group.

After the trial test, each participant was introduced to the experiment. The experiment consisted of a context, a story that describes the context, and a who-question presented to the subject at the end of the story. The experiment was shown in digital video format in a computer CD-ROM. The conditions of the experiment were one lexical aspect type-telic, and one grammatical aspect type-perfective, carried by the preterite tense. The two telic verbs used in the task were, pintar 'paint' and construir 'build'. The events describing the telic verbs were: PAINT THE WALL, and BUILD A ROBOT. For each event, the participants had to select between an ongoing situation and a completed situation. The PAINT THE WALL event presents two children, each painting a wall. As the story is told, the movie shows both children at the ongoing event of painting, i.e., the participant sees both children painting each a wall with a paint roller-brush. Then, as the story ends and before the question 'who painted the wall?' is asked, the screen splits and shows one child ongoing (still painting 
the wall), and the other stopped (done painting the wall) showing to the camera the paint roller, indicating that he has finished painting the wall. The background for the boy who is still painting the wall continues to be the same color, whereas the background for the boy who has finished painting the wall, has changed color and contains some decorative stars. In either case, the object of the event-the walls, are not seen in their entirety. In the ongoing event, the movie shows only the part that it is being painted. In the completed event, only the part behind the standing boy is shown. In other words, when the story ends and the question is asked, the participants cannot see the full outcome of the completed event-the whole painted wall.

The following story was used in the painting event:

Estos niños tienen que hacer un trabajo bien grande. Cada uno de ellos tiene que pintar una pared. Ves, cada uno está trabajando. Ya llevan un rato trabajando. ¿Quién pintó la pared?

'These boys have a big job to do. Each one has to paint a wall. See, each one is working. They have been working for a while now. Who painted the wall?'

Answer: the boy who holds the paint roller to the camera and is not longer painting.

The BUILD A ROBOT event shows two children building a robot each. Both children have pieces of the robot on the table. As the story is told, one of the children finishes the robot and shows the finished robot to the camera, while the other child continues building the robot. In this event, the objects-both robots-are shown in their entirety, i.e., when the story ends and the question is asked, participants see the entire built robot, and the entire ongoing building robot. The following story was used in the building event:

A estos chicos les gusta hacer robots. Cada uno quiere hacer un robot. Ves, éste tiene piezas en la mesa, y éste otro también. Ya llevan un rato trabajando. ¿Quién construyó el robot?

'These boys like to make robots. Each one wants to build a robot. See, this one has some pieces on the table, and this one too. They have been working for a while. Who built the robot?

Answer: the boy who shows the finished robot.

The events that describe the telic predicates PAINT THE WALL, and, BUILD A ROBOT were alternated with atelic predicates, i.e., one telic predicate was not followed by another telic predicate, but by an atelic predicate. Since this study only reports on the acquisition of the perfective in telic predicates, atelic predicates will not be discussed in this article.

\section{Results}

The results for both events are presented in percentages in the table below. Event 1 refers to the painting event. Recall that in this event, the agent is seen engaged in painting the wall, but the full change of the state of the object is not completely shown in neither case, the ongoing situation, nor the completed situation. Event 2 refers to the bulding event. In this event the agent is also seen engaged in building the robot, and the change of state of the object is shown in both situations, the ongoing and the completed situation. 


\section{Comprehension I}

Table 3. Results of Telic-Perfective in \%

Selection between Completed/Ongoing

\begin{tabular}{lcc} 
Age & Event 1'paint' Event 2 'build' \\
\hline \hline Adults & 100 & 100 \\
$3-4$ & 36 & 64 \\
$5-6$ & 35 & 94 \\
$7-8$ & 69 & 92 \\
\hline \hline
\end{tabular}

In the painting event, while adults scored 100\%, children aged 3-4 and 5-6 performed very poorly. It appears then that checking if the object sizes up the event as a whole, plays a role in children's assessment of a completed situation. Clearly, adults did not use the same strategy as the children. Adults know that the Spanish perfective morpheme -o entails the completion of the event. Therefore when selecting between completed/ongoing, they understand that the entailment of completion is represented by the painter who is holding the roller to the camera and has stopped painting because he is done, and not the painter who is still painting. The young children on the other hand, in order to validate a completed event, they needed to assess the full change of state of the object, and since that was not available they made the wrong selection. Now compare event 1 with event 2, the building robot event. In this event the change of state of the object is clearly observable. Here, adults scored $100 \%$, the youngest group performed almost target-like behavior 64\%, and the 5-6 and 7-8 year-olds performed like adults. Clearly, the ability to assess the change of state of the object played a role on the strategy of learning which robot building event was completed.

\subsection{Experimental Design of Comprehension Task II}

We have seen that the ability to evaluate the full change of the state of the object in a completed event is strategically important in the acquisition of aspectual information. The goal of the second comprehension test was to examine if the involvement of the agent in the event or its presence in the outcome of the event could also play a learnability role on the acquisition of the semantics of perfective aspect.

\section{Participants}

The same children subjects that participated in comprehension task I, also participated in comprehension task II. However, the adult results were drawn from a different group than the group from comprehension I.

\section{Procedure and Materials}

The conditions of this experiment were the same as the conditions for comprehension I: one lexical aspect type-telic, and one grammatical aspect type-perfective. The preterite tense was used as the perfective tense. However, in this experiment participants had to select between an incomplete/completed situation instead of an ongoing/completed situation of comprehension I. The two telic verbs used in the task in the perfective were, construir 'build' and hacer 'make. The events describing the telic verbs in the perfective were BUILD A SCHOOL TOWER, and MAKE A DOOR, which were alternated with telic predicates in imperfective aspect, but since this article reports on the acquisition of perfective aspect, the telic predicates in the imperfective will not be commented upon.

This experiment consisted of a story that describes a situation and a which-question stated in the perfective at the end of the story. The child's task is to match the question with the 
completed event. The experiment was not shown in digital video format, instead toys and pictures were used, the pictures were presented in the computer screen.

After the participants were explained the procedure, they were introduced to four animal characters that want to build a school. Each animal wants to take part in building the school, so each one selects what he wants to do (e.g., the cow wants to draw the plans of the school, the sheep wants to build the school tower, the horse wants to paint the walls, the pig wants to make the door). At the end of the story each animal says in an I-statement what he did (e.g., I built the school tower). At that point, the subject is presented with a picture that contains a completed outcome (e.g., a tower that has been finished), and an incomplete outcome, (e.g., a tower that is half built). Then, the participant is asked a which-question that leads him to select one of the outcomes presented in the picture. For example, when the sheep says I built the school tower, the subject was presented with the picture that contains both outcomes and was asked which tower is the sheep talking about? Each animal with it's Fstatement, the outcome picture, and the question, is introduced in turn. The animals in the story were never seen engaged in constructing any part of the school, i.e., they only talk about it. When the story ends and the picture of the outcome is introduced, the characters of the story are not standing next to the object they said they built. In other words, the participants are not led in their decision by reading the intentions of the agent, either as the situation develops or in the final outcome. The example below is the story used in the experiment:

La vaca, la oveja, el caballo, y el cerdo quieren ir al colegio, pero no pueden porque no hay colegios para ellos. Entonces ellos deciden construir un colegio. Cada animal quiere hacer una parte. La vaca decide dibujar los planes del colegio. La oveja decide construir la torre del colegio. El caballo quiere pintar las paredes. Y el cerdo quiere hacer la puerta. La oveja dice: yo construí la torre del colegio.

¿Cuál de las dos torres esta hablando la oveja?

'The cow, the sheep, the horse, and the pig want to go to school, but they can't because there is no school for them. So they decide to build their own school. Each animal wants to do a part. The cow decides to draw the plans of the school. The sheep decides to build the school tower. The horse wants to paint the walls. The pig wants to make the door. The sheep says: I built (PERF.) the tower of the school.'

Which one of the two towers is the sheep talking about?

Results

The following table contains the results of comprehension II. Event 1 refers to the building of the tower event, and event 2 represents the results from making the door event as they are shown on the table.

\section{Comprehension II}

Table 4. Results of Telic-Perfective in \%

Selection between Completed/Incomplete

Absence of Agent

\begin{tabular}{lrr} 
Age & Event 1 'build' Event 2 'make' \\
\hline \hline Adults & 100 & 100 \\
$3-4$ & 64 & 57 \\
$5-6$ & 94 & 82 \\
$7-8$ & 100 & 100 \\
\hline \hline
\end{tabular}


While adults scored $100 \%$ in both events, the 3-4 year-olds scored just above chance for both events, performing non-target like behavior. The results in this second comprehensive experiment clearly indicates again that at the age of 3-4, children still have difficulty determining perfective meaning from perfective morphology. Although children aged 5-6 performed within target, they had more difficulty with event 2 . This is probably due to the irregular morphology of the verb hacer 'do' in the preterite tense, and not to the absence of the agent's involvement. Children 7-8 performed like the adults.

\section{Interpretation of results of comprehension tasks I and II}

The adult pattern indicates that when selecting between ongoing/completed situations in which the object's change of state is not fully shown, adults know, by simply paying attention to perfective morphology alone, which event was the completed event, and which one was the ongoing one. That is, adults do not need to check if the object measured out the event as a whole. Young children, however, showed that when perfective morphology is used to talk about completed situations, children do not rely on just the morphology to interpret the situation, but also on their ability to obtain a full account of the object's change of state. During the experimental procedure, some of the children were asked by the experimenter why they had selected the ongoing painter, to what they replied that they had selected the ongoing painter because the other painter had stopped painting. In other words, these children were interpreting a completed event as a terminated event because the object's change of state was not fully observable, and they assumed that the ongoing event had a better chance to be completed because it was still ongoing. It appears that under these circumstances, young children know that perfective morphology marks the entailment of completion, and as such, they are compelled to search for the result that would confirm their ongoing analysis. If their predictions are not matched, they opt for the next possible analysis, which in this particular case led them to the wrong response. This concept of figuring out if the object measures out the event as a complete whole is a learnability factor that plays a role in the acquisition of semantic morphology. In predicting telic predicates and understanding that perfective aspect entails the completion of an event, children need to learn the grammatical relations between object and event, that is, that argument structure and event structure are intrinsically connected. And not only must they consider the arguments' relation, but how those things are represented in the world. The significance of the role of the object as being perceived as the measurer of the event, can be verified by the results obtained from event 2 , the robot building event, in which the object's change of state is fully viewed and therefore accounted for. In this event $64 \%$ of children aged 3-4 answered correctly, while children 5-6 performed within target $94 \%$ of the time which is significantly higher than their performance in the wall painting event.

In the second comprehension experiment where participants had to select between completed/incomplete, the absence of the agent was not a deterrent for adults in assessing a completed situation from perfective morphology. The 3-4 year-olds performed equally just above chance in both events which is not within target. This is an indicative that while reading the agent's intentions may play a role in assessing the entailment of completion in a telic predicate, the presence of the agent is not as much of a crucial determinant as is the presence of the full view of the change of state of the object as we saw in the previous task. The results of the second comprehension task also show that the different methodologies of both comprehension tasks brought about similar results, which confirms that, young children's difficulty in determining perfective meaning from form is not due to methodology but to learnability and cognitive factors. The results obtained from children aged 5-6 are consistent with the results from comprehension I, event 2, which also indicates that agency cues are not a significant element in interpreting the entailment of completion. Based on the results of both 
comprehension tasks, the presence of the object plays an important role in factoring out the entailment of completion. Young children's knowledge of perfective semantic morphology showed to be about the same in both comprehension tasks; their results were just above chance but not within target, either when selecting between completed/incomplete or when selecting from ongoing/completed. Children aged 5-6 understood the semantics of perfective morphology and performed slightly better when they selected from ongoing/completed than between completed/incomplete (if we don't take into consideration the absence of the object in event 1). Children 7-8 year-old performed well in both types of selection.

\section{Discussion and Conclusion}

This study contributes to the research on children's acquisition of aspect by presenting data on the acquisition of Spanish aspect in production and in comprehension. In summarizing the results of this study, the successful performance on the comprehension of Spanish perfective aspect takes place around the age of 5-6. A finding which, came as a surprise, was that young learners of Spanish, the 3-4 yr-olds, performed non-target like behavior-although they barely fell short of coming within target-in comprehension as well as in production. Another surprising result was the production results of the 5-6 year-olds. Children aged 5-6 also fell below target on the distribution of perfective morphology according to lexical type, recall that they overextended imperfective tense when talking about completed situations.

Studies on the acquisition of the semantics of Polish and Russian, children showed knowledge of aspectual entailments at an early age, around the age of 2;6, which is significantly younger than the successful performance of the learners of Spanish. Why learners of Spanish didn't perform like the Polish or Russian learners? Studies in English, and in Dutch have also shown children's acquisition of the semantics of the language at a later age than 2;6. Then one may ask, why is there such an age discrepancy on the acquisition of aspectual meaning? Could it be that the encoding of aspectual information is more readily accessible in one language than another? van Hout (in press) has proposed that the acquisition of telicity appears to be easier in languages that mark the entailment of completion on the verb itself, such is the case of Slavic languages (Russian, Polish) in which perfective aspect is marked as a prefix on the verb, than in languages that telicity is marked by the combination of the properties of the verb and its object, as in the case of Germanic languages and Finnish. Spanish is also a language where the entailment of completion is obtained from the properties of the verb and its arguments, in particular its direct object. van Hout distinguishes between what she calls predicate telicity and compositional telicity. Languages like Russian and Polish have predicate telicity in which the entailment of completion is calculated by the verb + affix, whereas, languages like English and Dutch have compositional telicity in which the completion of the event is computed based on the joint properties of the verb + object.

The data presented in this study suggests that the arguments of the verb, particularly the direct object, play a significant role on learning the entailment of completion carried by perfective morphology. The presence of the agent may play a small role in acquiring aspectual meaning, however the data shows that it was not as a strong of an indicator as was the presence of the full change of state of the direct object. In order to understand the entailments of completion of Spanish perfective aspect, young children must calculate the compositional properties of the verb phrase, which includes the quantized reference of the noun phrase (the direct object), the morphology on the verb, which marks perfective aspect and past tense at the same time, and, must confirm that their ongoing analysis matches the results obtained in the direct object. The data shows that when young children cannot confirm their ongoing analysis, they get confused and give the wrong answer. A possible explanation to the late attainment of 
aspectual meaning may rest upon figuring out how the outcome of the direct object affects the total result in the semantic equation. It appears that it is through the mechanism of checking local cues that children may master the conceptual domain of aspect, in particular perfective meaning. It is not clear at this point that the learning of aspectual meaning in Slavic languages may require the same learnability procedure as the one presented here, at any rate, it should be considered, for it may bring forth an explanation to the age discrepancy in the acquisition of semantic morphology.

\section{References}

Aksu-Koc, A. (1988): The acquisition of aspect and modality. Cambridge: C.U.P.

Antinucci, F. and R. Miller (1976): How Children Talk about What Happened. Journal of Child Language 3, 167-189.

Behrens, H. (1993): The relationship between conceptual and linguistic development: the early encoding of past reference by German children. CLS29, Parasession on conceptual representation, Vol. 2, 63-75.

Berman, R. (1983): Establishing schema: children's construals of verb-tense marking. Language Sciences 5, 6178.

Bloom, L., Lifter, K. and Hafitz, J. (1980): Semantics of verbs and development of verb inflection in child language. Language 56 (2), 386-412.

Bronckart, J.P. and H. Sinclair (1973): Time, Tense and Aspect. Cognition 2(1), 107-130.

DeLemos, C. (1981): Interactional processes in the child's construction of language. In Werner Deursch (ed.): The child's construction of language. London: Academic Press.

van Hout, A. (in press): Imperfect imperfectives: On the acquisition of aspect in Polish. In P. Kempchinsky and R. Slabakova (eds.): Aspectual Inquiries. Dordrecht: Kluwer.

- (in press): Acquiring telicity crosslinguistically. On the acquisition of telicity entailments associated with transitivity. In M. Bowerman and P. Brown (eds.): Crosslinguistic perspectives on argument structure: Implications for learnability. Hillsdale: Lawrence Erlbaum.

Kamp, H. and C. Rohrer (1983): Tense in Texts. In R. Bauerle, C. Schwarze, \& A. von Stechow (eds.): Meaning, Use and Interpretation of Language. Walter de Gruyter, Berlin.

Li, P. (1990): Aspect and aktionsarten in child Mandarin. PhD dissertation, Leiden, The Netherlands.

Stoll, S. (1998): Acquisition of Russian Aspect. First Language 18, 351-377.

Vinnitskaya, I. And K.Wexler (2001): The role of pragmatics in the development of Russian aspect. First Language 21: 62, 143-186.

Wagner, L. (1997). Syntactic and Semantic Development of Viewpoint Aspect. Proceedings of the GALA 97 Conference on Language Acquisition. Edinburgh, UK.

- (2002): Understanding completion entailments in the absence of agency cues. Journal of Child Language 29, 109-125. Cambridge University Press.

Weist, R., H. Wysocka and P. Lyytinen (1991): A cross-linguistic perspective on the development of temporal systems. Journal of Child Language 18, 67-92. 